\title{
Peer-mentoring through the Biomedical Engineering Design Curriculum
}

\section{Samantha L McCarthy, University of Wisconsin - Madison}

Samantha L. McCarthy received her B.S. degree in Biomedical Engineering from the University of Wisconsin - Madison in 2015. She served as Chair of the Biomedical Student Advisory Committee (BSAC) in 2015 .

\section{Mr. Reed T. Bjork, University of Wisconsin - Madison}

Fifth year senior studying Biomedical Engineering at the University of Wisconsin - Madison specializing in cellular and tissue engineering. Current chair of the Biomedical Student Advisory Committee (BSAC).

\section{Tasnia Tabassum, University of Wisconsin - Madison}

Tasnia Tabassum is a third-year biomedical engineering student at the University of Wisconsin - Madison. She is pursuing the healthcare systems and cellular tissue engineering specializations of biomedical engineering and also has interests in global health. This year, she is on UW-Madison's Biomedical Engineering Society (BMES) board as the Counseling and Resources for Undergraduates in Science and Engineering (CRUISE) Chair.

\section{Dr. John P Puccinelli, University of Wisconsin - Madison}

Dr. Puccinelli is the Associate Chair of the Undergraduate Program in the Department of Biomedical Engineering. He began here as student near the start of the UW-BME program and earned his BS, MS, and $\mathrm{PhD}$ in BME. He is interested in hands-on instruction - teaching and developing courses related to biomaterials and tissue engineering, as well as design. He was awarded the BMES Student Chapter Teaching Award in 2011, 2013-2015 and the Polygon Outstanding BME Instructor Award in 2012 and 2015. 


\section{Peer-mentoring through the Biomedical Engineering design curriculum}

Biomedical Engineering (BME), has been listed as the number one best job by CNN Money in 2012-2014, ${ }^{1-3}$ best job in healthcare ${ }^{4}$ and most valuable college major by Forbes,${ }^{5}$ among other top listings, ${ }^{6-10}$ and is a rapidly growing field. This growth is expected to be well above average at $27 \%$ from 2012-2022 as projected by the Bureau of Labor Statistics. ${ }^{11}$ As a result, BME programs are also growing with the demand. Our BME undergraduate program at the University of Wisconsin-Madison, which has historically encompassed sophomores and above, has more than doubled in the last five years. This year, our college has moved to a direct department admission model adding an additional surge of freshman directly to the program (78\% more students) with progression requirements versus a secondary application.

In an effort to create an inclusive and welcoming environment for these 240 freshman, we have developed a mentorship program integrated with our design curriculum. The undergraduate program here was founded with design at the heart of the curriculum. We developed a rigorous six-semester, team-based design sequence for our undergraduates to solve real-world, clientbased design problems that result in physical prototypes at the end of each semester. Students begin this sequence as first semester sophomores. Sophomores are teamed with juniors for their first semester of design. This breaks down class boundaries and forms mentored relationships between sophomores and juniors in the department. For the second design semester in the sequence, sophomores engage in a guided design fundamentals course ${ }^{12}$ followed by mentoring sophomores in the third semester. The fourth, fifth and sixth semesters in the design sequence involve students working with peers of the same age generally for a three-semester long project.

The design sequence actively involves each student in the evolution of the design course and department through our Biomedical Student Advisory Committee (BSAC). In BSAC, one member from each of the design teams (54 teams in fall 2015) serves as a BSAC representative, thereby providing representation for all BME majors-sophomore through senior year. BSAC meets twice per month throughout each semester. Utilizing this design backbone, our department with our BSAC Chair and Biomedical Engineering Society (BMES) Student Chapter's Counseling and Resources for Undergraduates in Science and Engineering (CRUISE) Chair developed a new layer of mentoring in our curriculum. This year, we matched freshman students with BSAC members as mentees/mentors.

Mentor matching was facilitated by surveys (one to the freshmen and the other to BSAC members and the upper classes). Prior to the start of the semester, students in BME Design (sophomore-senior) were made of aware of this new program and the new role of the BSAC representative. Both groups were asked to indicate their intended track within BME, future plans, and the option to list other interests. We achieved a $100 \%$ response rate from the BSAC members with an additional $13 \%$ of the remaining design students volunteering to be mentors for the $91 \%$ of the freshman interested in having a mentor. This equated to two-three mentees per mentor.

Through integrating the mentorship program with the design curriculum and BSAC we are able to discuss the 'freshman experience' in our BSAC meetings, answer common questions, and 
effectively integrate the freshmen into upper-level, real-world design experiences that are closely advised by faculty where each team of 4-5 design students meets weekly with their faculty advisor. This new program enhances student-student interactions already established in our design curriculum such as the sophomore-junior hybrid teams and our senior student assistants who facilitate our sophomore design fundamentals course. This paper will discuss the process of developing the mentor and freshman mentee relationship, results based on the students' experiences, and the benefits of establishing a mentorship philosophy within the curriculum.

\section{Developing the mentor and mentee relationship}

The first step in establishing the mentorship program was developing the mentor and mentee relationship. As outlined previously, one member of each design team holds the BSAC role. Before deciding on team roles, students were made aware of the connection between the BSAC role and mentorship responsibilities. In addition, any student in the BME department could volunteer to be mentors. This group collectively made up the mentors in the program. Mentors represented each of the five track/emphasis areas within the BME department, including: Medical Instrumentation, Medical Imaging, Biomechanics, Biomaterials/Cellular/Tissue Engineering, and Health Care Systems. New freshmen were invited to participate in the new mentorship program on a voluntary (though highly encouraged) basis. Of the 240 incoming freshmen, 218 were interested in having a mentor. These participants make up the mentee group.

In order to match mentees and mentors with similar interests and BME related goals, all participants took surveys. These surveys indicated their intended track/emphasis within BME, future plans such as study abroad, industry, medical school, other pre-health programs, $\mathrm{PhD}$ program, business school, other post-graduate programs, and the option to list other interests such as research lab experience or industry experience. Using the data from these surveys, mentees were matched to mentors with similar future goals or experiences. The students were first matched based on their intended specialization within BME. The students were then matched by interest in professional school, grad school, or industry. Consideration was also given to survey responses regarding research interests, possible double majors and certificates, internship and co-op interests, and other hobbies. After matching, mentors and mentees were sent an email with information about the goals and requirements of the program:

\section{Hello BME Mentors,}

The matching/sorting process is complete (see attached) - thank you to our sorting hats: Biomedical Student Advisory Committee Chair and BMES CRUISE Chair.

In your individual welcome email, it would be valuable to include the following:

- Welcome your mentee to the College of Engineering and congratulate them on being admitted to BME.

- Let the mentees know they can ask to meet with you or ask questions anytime. Let them know that you will initiate at least 4 meetings.

- Let the mentees know you are a resource for scheduling, learning about design, navigating the COE, career/advanced education opportunities in BME etc.

In your meetings this semester, it would be valuable to discuss the following:

- Ask them why they chose BME and if their plans have changed to another discipline.

- Ask about their first few weeks here on campus (so we can gather info about the "Freshman" experience). 
- Tell them about your research/design project/extracurricular activities.

- Ask them if they have attended any BMES events, perhaps invite them to attend with you

- Find out about other activities they would like to be involved in within the mentorship program, BME, and UW in general.

- Bring these thoughts and your experience back to BSAC.

If they have questions about BME Progression requirements and the General College Requirement: Please direct your mentees to their advisor.

We very much appreciate your participation in welcoming the next BME class here to UW and helping them acclimate to college.

The program was voluntary for the mentees, but mentors and BSAC representatives had to fulfil basic requirements as part of their role in the design sequence. As such, mentors were encouraged to meet with mentees at least four times in the semester. The cadence and activities or topics for discussion were left up to each mentor and mentee group.

After matching, the mentorship program could formally begin. First, mentors were encouraged to email their mentees to welcome them to the $\mathrm{COE}$ and provide additional information about the mentorship program. Mentors interfaced with mentees in a variety of ways. These include small group meetings, one on one sessions, communication over email, and communication through text messages. The method of communication was again left up to each mentor and mentee group. Mentors were available for questions regarding a variety of topics as listed above. In addition, mentors were encouraged to ask mentees about why they chose BME and how they were adjusting during their first few weeks on campus. Many mentors chose to meet with their mentees on the engineering campus and introduced them to various facilities within the college. It was strongly encouraged that mentors discuss their current design projects with mentees. Mentors were encouraged to invite mentees to design team meetings and show them their design project prototypes, as well as inviting them to attend design presentations.

BSAC and BMES encouraged group events for mentors and mentees to attend together. In the beginning of the year, there was a large kickoff event held for students interested in BMES, through which many students were able to network. BMES hosted a class advising session a few weeks before most freshmen started scheduling. During this event, upperclassmen spoke to the freshmen in attendance about elective options, course rigor, and scheduling layout. In addition, some mentors and mentees attended a pumpkin carving event open to all students at the university. BMES general meetings were also a twice monthly occurrence, when mentors and mentees were able to connect. Study jams were also held by BMES during final exam week, which provided another meeting space for mentors, mentees and all BME students. Overall, these events were successful for the mentor and mentee groups who attended.

\section{Results based on students' experiences}

Near the end of the semester, the mentor group was asked to describe their interaction with each mentee in a Communication Tracking Survey and to complete an anonymous exit survey regarding their experience. We received a 95\% response rate in the Communication Tracking Survey (Figure 1) and a 70\% response rate to the exit survey. The mentee's completed a similar exit survey with a $41 \%$ response rate. 


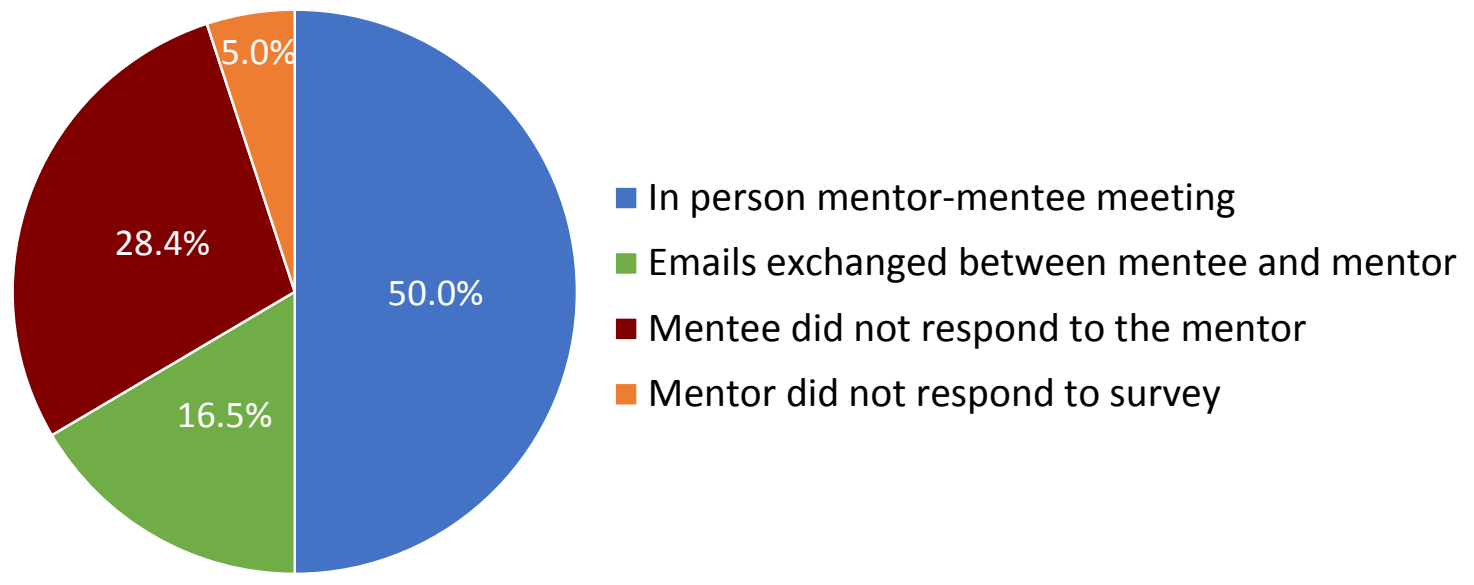

Figure 1: Results of mentor and mentee communication tracking survey. Of the freshman who opted into the mentorship program $66.5 \%$ of them communicated with their mentor while $28.4 \%$ never responded the mentor according to the mentors. Five percent of mentee group had mentors who did not respond to our survey, thus their interaction with their mentees is unknown.

Based on the communication tracking survey, mentors met in person with $50 \%$ of mentees, only emailed with $16.5 \%$, and did not get responses from $28.4 \%$ of mentees (Figure 1). These results indicate that $66.5 \%$ of mentees received direct mentorship from their mentors. While this percentage shows room for improvement, it is worth noting that these 145 freshmen received personalized mentoring from an upperclassmen in their field. Many mentors indicated that they did not hear back from their mentees. Later it was discovered that the welcome email sent by Mentors differed vastly and some Mentors left the communication open with statements such as "If you would like to meet up and chat about how your first semester is going so far, or ask any questions, please let me know!" To encourage further communication and at least one meeting, BSAC is drafting a standard welcome email template that will include suggested meeting times thus encouraging at least a first meeting. From the exit survey, it is important to note that some mentors and mentees expressed that they were more comfortable exchanging emails versus meeting in person, so both groups represent potentially effective mentorship. The most popular topics of discussion for mentors and mentees included: class scheduling/advising, determining BME emphasis/track, why they chose BME, campus research, design projects, involvement in BMES, and internships and co-ops. Mentors and mentees also reported discussing the transition to college and everyday topics.

Overall, $92 \%$ of the mentors were at the junior level or above. Over $95 \%$ of mentors felt "Very qualified" (40\%) or "Qualified" (55\%) to be a mentor. At this point in the design sequence, juniors are typically working on their third semester of design projects. Mentors also reported that they enjoyed giving back to the department and fellow BME students. Additionally, 92\% of mentors reported that they thought that the time spent with their mentee was "very useful" (20\%) or "useful" (44\%) for their mentee or they were "neutral" (28\%). Similarly, the mentees felt that their interaction was "very useful" (58\%) or "useful" $(17 \%)$ while others did not find the interaction helpful (14\%) as of yet. 
As a part of the Mentee Exit Survey, they were asked several questions in order to rank their confidence (scale 0-5 from not-confident to very-confident) in a number of areas both before and after mentoring. This was designed to measure the improvement of outcomes from the mentoring experience. The results to three of these questions are presented below in Figures 2-4.

Figure 2 shows the mentee responses to the question "Rank your confidence on the following statement: I know BME is the right department for me" BEFORE and AFTER the mentorship program. As shown in the figure, the mean confidence of mentees increased from 3.06 to 3.43 after participating in the mentorship program.

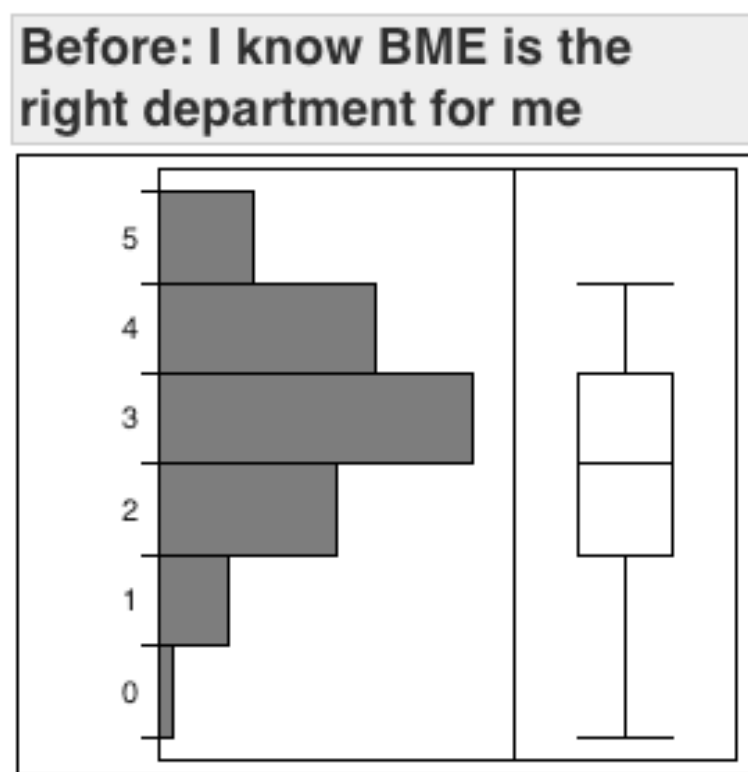

\section{Summary Statistics}

Mean $\quad 3.06$

Std Dev 1.16
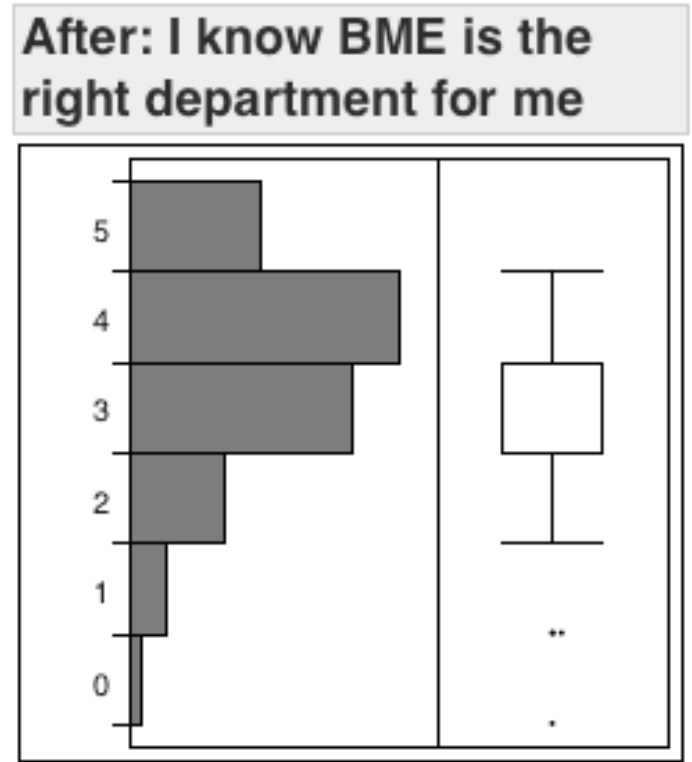

\section{Summary Statistics}

Mean $\quad 3.43$

Std Dev 1.15

Figure 2: Results of mentee confidence in their choice of BME. The distribution of mentee ranked confidence is shown, with an outlier box plot. The "After" box plot has a value of 4 for both the median and the 3rd quartile, so only a single box is shown.

Mentees were also asked to rank their confidence in the following statement as a result of their mentor meetings: "I know how to find resources if I am struggling in a course." The results of this question are shown below in Figure 3. The mean increased from 2.92 before meeting with mentors to 3.71 after meeting with a mentor. Helping new students learn about the supplemental instruction, tutoring, and other resources that are available to them is a clear strength of the program. 


\section{Before: Finding course resources}

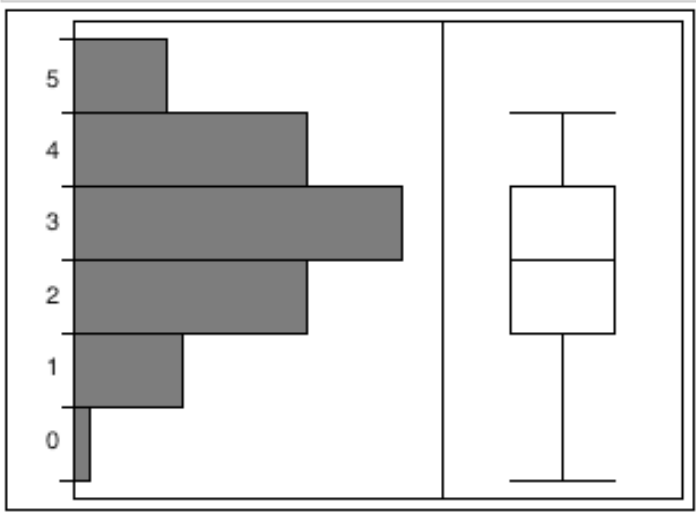

Summary Statistics

Mean 2.92

Std Dev 1.19

\section{After: Finding course resources}

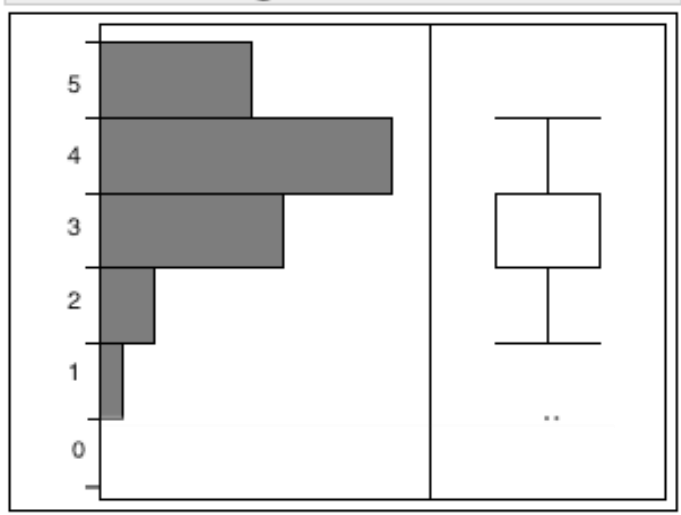

Summary Statistics

Mean $\quad 3.71$

Std Dev 1

Figure 3: Results of mentee confidence in finding course support resources. The distribution of mentee ranked confidence is shown, with an outlier box plot. The "After" box plot has a value of 3 for both the median and the 3rd quartile, so only a single box is shown.

Mentees were also asked to rank their confidence in the following statement: "I understand what kinds of employment or academic opportunities await me after graduation from BME.” The results show the mean confidence was 2.57 before meeting with a mentor, and 3.14 after meeting with a mentor. The distribution is shown in Figure 4. In fact, all questions asked in the manner showed improvement post meeting with a mentor.

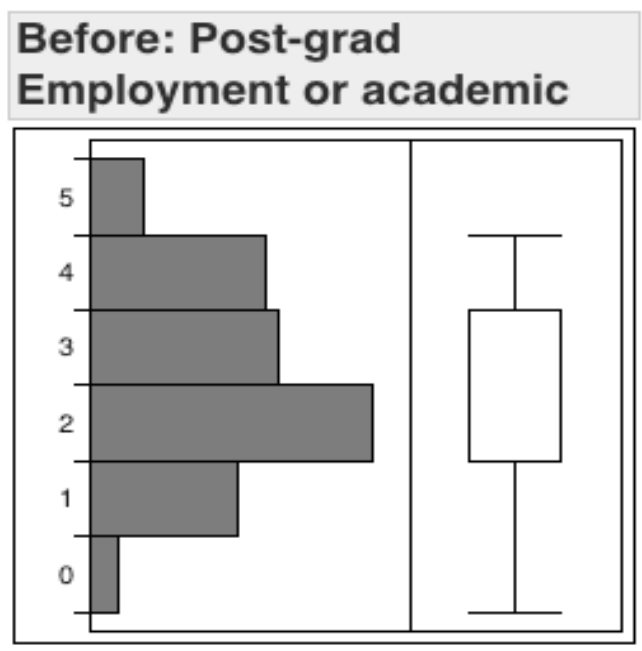

Summary Statistics

Mean 2.57

Std Dev 1.25
After: Post-grad Employment or academic

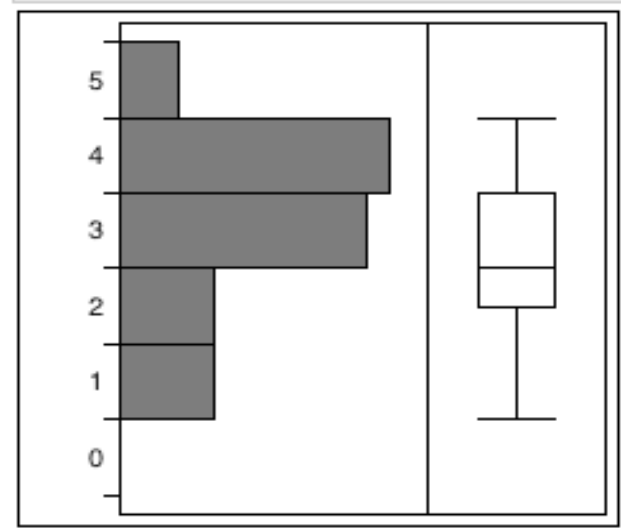

Summary Statistics

Mean $\quad 3.14$

Std Dev 1.13

Figure 4: Results of mentee confidence in opportunities after an undergraduate degree. The distribution of mentee ranked confidence is shown, with an outlier box plot. The "After" box plot has a value of 2 for both the median and the 1st quartile, so only a single box is shown. 
In addition, mentees were invited to comment about their perception related to the strengths of the program. One student mentioned: "Connecting with an upperclassman and other freshman was extremely helpful. I especially got to know the other mentees and we actually have a group chat and attend SWE events together. I would have never gotten to know these people without the program." Multiple other students appreciated the laid back and relaxed environment in which they could ask questions from their peers, and many also appreciated getting personal attention from their mentors. Another student reported, "[the program] helped me feel like I wasn't alone and that people do make it through".

The survey results pointed to areas for improvement of the program. One mentor suggested creating a reference document containing topics to discuss and links to resources. This would serve as a starting point for mentors at their first meeting. This document would also help clarify the distinction between the mentorship program, BMES, and BSAC. In addition, the program should host a group kickoff event during the first few weeks of the semester. In addition, general feedback pointed that sophomores may not have enough experience to be mentors, and thus the role should be reserved for juniors and seniors.

\section{Benefits of establishing a mentorship philosophy within the curriculum}

The benefits of the BME mentorship program are clear and numerous. This program helps foster a mentorship philosophy and ultimately networking within the curriculum, a critically important and unique aspect of the program. Since mentorship was already a key part of the design sophomore/junior level sequence, it is good to establish the mentoring mindset early. Many of the mentors expressed the "feel good" factor of giving back to the department and helping guide a new student. Mentors are able to put into perspective just how far they have come in their academic and personal development. Mentors are also able to learn more about the department when finding answers to their mentees' questions. Mentees also saw the value in the program and were thankful to have a mentor available for questions that otherwise may have gone unanswered.

In addition, the mentorship program helps to create networks within the freshman class. Some mentees mentioned getting to know their fellow freshmen through group dinners or meetings with their mentor. The freshmen created social media groups to attend COE events, thus beginning to build their network of engineers in their field.

Overall, there is sufficient interest in continuing and improving the BME mentoring program. Efforts will be made to sustain the program by clarifying the responsibilities of mentors and mentees, hosting more program wide mentor and mentee events, and increasing awareness of the program. Clarifying expectations of the members of the program will entail a more detailed and directed introductory email from the mentor to the mentee that encourages setting up a meeting to break the ice. Collaboration in future BSAC meetings will include composition of a general email template or outline for the mentors to follow that utilizes a personal yet directive approach to maximize the response from mentees. Mentorship events will include a more broad range of activities, possibly including volunteering and department events. The social, interactive atmosphere of these events will provide the mentees with an opportunity to reach out to other freshman students or mentors, thus creating a sense of comfort and support in the BME program. Planning and developing an event calendar is paramount in establishing a strong mentorship 
program, a goal that BSAC has made a priority for the upcoming year. Increasing awareness of the program will be focused on letting students know about the program during their summer Student Orientation, Advising, and Registration (SOAR) event. During this event, representatives will let students know about the established mentorship program for BME freshmen and collect mentee information and interests early to facilitate optimal matching. With these improvements, the mentorship program should continue to be a success through the collaborative efforts of the department, BMES and our student advisory committee (BSAC).

\section{References}

[1] "Best Jobs in America - 2012," CNN Money, 29 October 2012. [Online]. Available: http://money.cnn.com/pf/best-jobs/2012/.

[2] "Best Jobs in Ameraica - 2013," CNN Money, 12 November 2013. [Online]. Available: http://money.cnn.com/pf/best-jobs/2013/.

[3] "Best Jobs in America - 2014," CNN Money, 2014. [Online]. Available: http://money.cnn.com/pf/bestjobs/2014/.

[4] S. Adams, "The Best Jobs In Health Care In 2014," Forbes, 3 December 2013. [Online]. Available: http://www.forbes.com/sites/susanadams/2013/12/03/the-best-jobs-in-health-care-in-2014/.

[5] J. Goudreau, "15 Most Valuable College Majors," Forbes, 1505 2012. [Online]. Available: http://www.forbes.com/pictures/lmj45jgfi/no-1-biomedical-engineering/.

[6] "Jobs Rated 2013: Ranking 200 Jobs From Best To Worst," Career Cast, 2013. [Online]. Available: http://www.careercast.com/jobs-rated/best-worst-jobs-2013.

[7] "Jobs Rated 2014: Ranking 200 Jobs From Best To Worst," Career Cast, 2014. [Online]. Available: http://www.careercast.com/jobs-rated/jobs-rated-2014-ranking-200-jobs-best-worst.

[8] "Jobs Rated Report 2015: Ranking The Top 200 Jobs," Career Cast, 2015. [Online]. Available: http://www.careercast.com/jobs-rated/jobs-rated-report-2015-ranking-top-200-jobs.

[9] "Best and Worst Jobs of 2013," Wall Street Journal, 22 April 2013. [Online]. Available: http://www.wsj.com/video/best-and-worst-jobs-of-2013/9BA568F8-9466-4ED5-9420E9B18C321148.html.

[10] C. Gandel, "Discover 11 Hot College Majors That Lead to Jobs," US News and World Report, 10 September 2013. [Online]. Available: http://www.usnews.com/education/best-colleges/articles/2013/09/10/discover11-hot-college-majors-that-lead-to-jobs.

[11] "Occupational outlook handbook - Biomedical Engineers," United States Department of Labor: Bureau of Labor Statistics , 17 December 2015. [Online]. Available: http://www.bls.gov/ooh/architecture-andengineering/biomedical-engineers.htm.

[12] A. Nimunkar, J. Puccinelli, M. Bollom, W. Tompkins.. "Using a Guided Design Project to Motivate BME Sophomore Students to Learn Multidisciplinary Engineering Skills.," in Proceedings of the American Society for Engineering Education Annual Conference, Indianapolis, IN, 2014. 